\title{
A genetic linkage study of a kindred with X-linked retinitis pigmentosa
}

\author{
S S BHATTACHARYA, ${ }^{\prime}$ J F CLAYTON, ${ }^{\text {P }}$ S HARPER, ${ }^{2}$ G W HOARE, ${ }^{3}$ \\ M R JAY, ${ }^{4}$ A L LYNESS,${ }^{4}$ AND A F WRIGHT ${ }^{1}$
}

From the 'MRC Clinical and Population Cytogenetics Unit, Western General Hospital, Edinburgh EH4 2XU; the ${ }^{2}$ Section of Medical Genetics, Department of Medicine, Welsh National School of Medicine, Heath Park, Cardiff CF4 $4 X N$; the ${ }^{3}$ Eye Department, Nevill Hall Hospital, Abergavenny, Gwent; and ${ }^{4}$ Moorfields Eye Hospital, City Road, London EC1V 2PD

SUMmARY A large kindred with X-linked retinitis pigmentosa (XLRP) was investigated clinically and by means of genetic linkage with a view to developing methods of carrier detection and early diagnosis. A restriction fragment length polymorphism, identified by recombinant DNA probe L1.28, showed close genetic linkage to XLRP in this kindred and is a potentially useful marker for the purposes of genetic counselling.

In 1965 a family was described, consisting of seven daughters and three sons, whose father had died after being certified blind from an unknown cause.' The three sons were normal and two had normal children; the third was unmarried. Each of the seven daughters had one or more sons suffering from retinitis pigmentosa ( 10 in all). Since then two of their daughters have had affected sons (Fig. 1).

Initially there was some doubt whether this family should be classified as $\mathrm{X}$-linked retinitis pigmentosa (XLRP), as in no case did the carriers show a tapetal reflex, which was believed at that time to be the characteristic fundus appearance of the carrier state.

Correspondence to Dr M Jay, Moorfields Eye Hospital, City Road, London EC1V 2PD.
In addition several of the proved carriers showed retinal pigment epithelial changes with associated visual loss, which was severe in some cases. It has been recognised since then that female carriers may show changes other than a tapetal reflex and may have a visual deficit. ${ }^{2-4}$ The pattern of inheritance in this kindred, associated with severe visual deficit and choroidal atrophy in advanced disease in affected males and variable visual function in the females, is compatible with a diagnosis of XLRP. It is reasonable to assume that the blind progenitor of this family (I/1) suffered from XLRP, which has therefore now occurred in four generations.

$\mathrm{X}$-linked retinitis pigmentosa is due to an abnormal gene on an $\mathrm{X}$ chromosome. Males with one

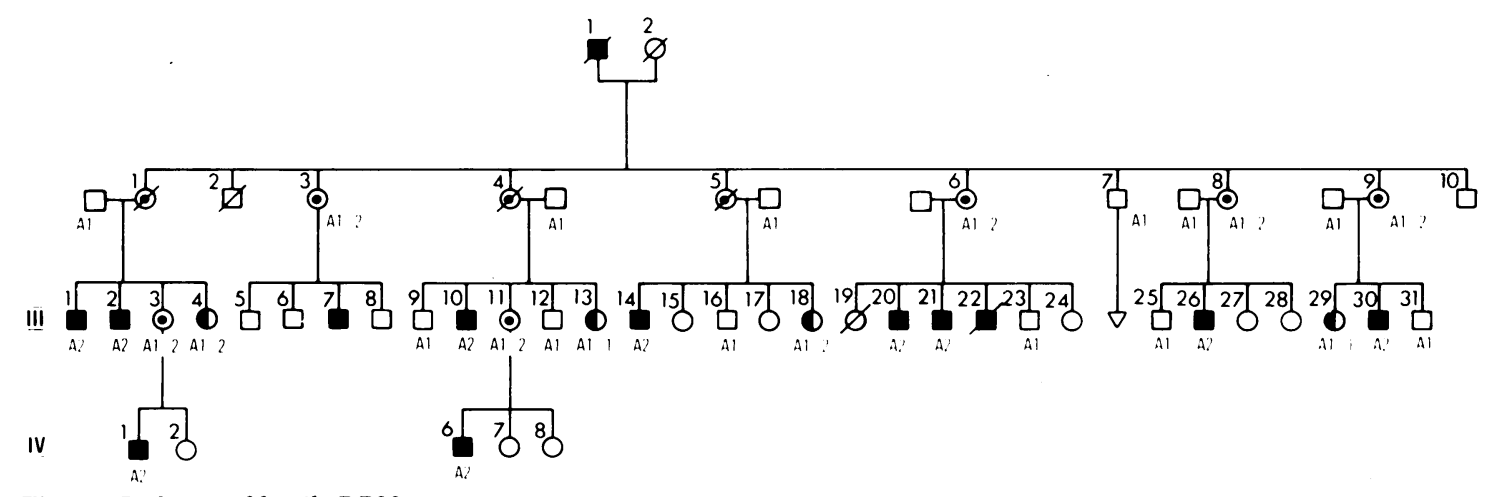

Fig. 1 Pedigree of family RP22. 


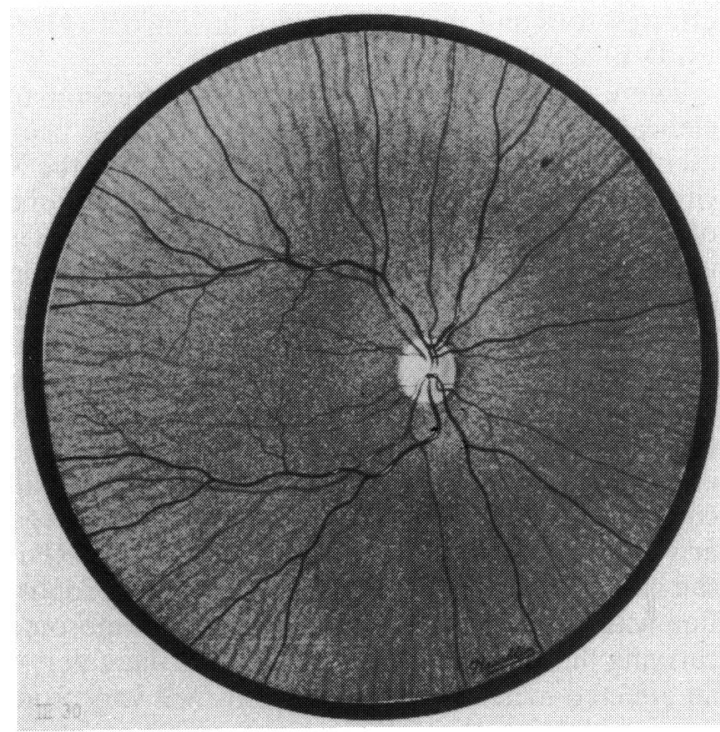

Fig. $2 a$

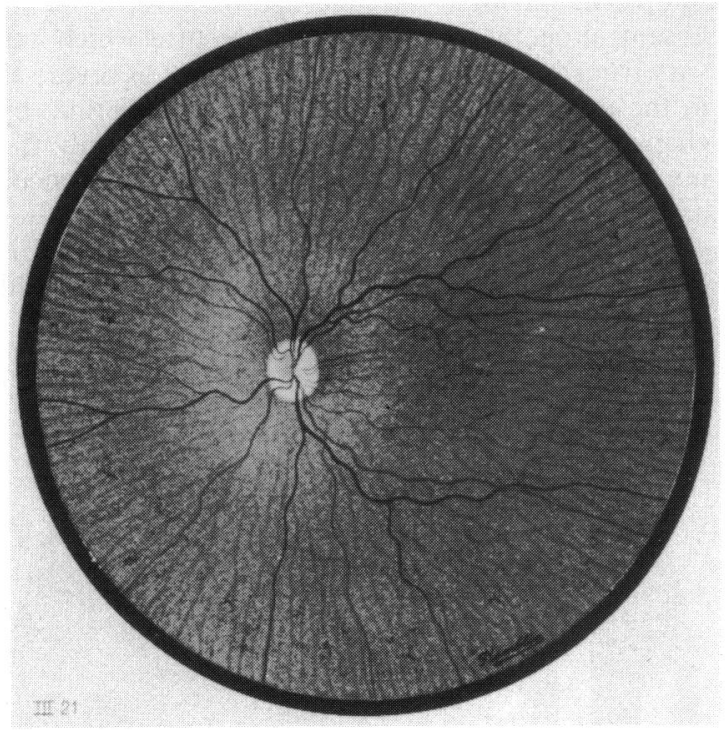

Fig. 2c

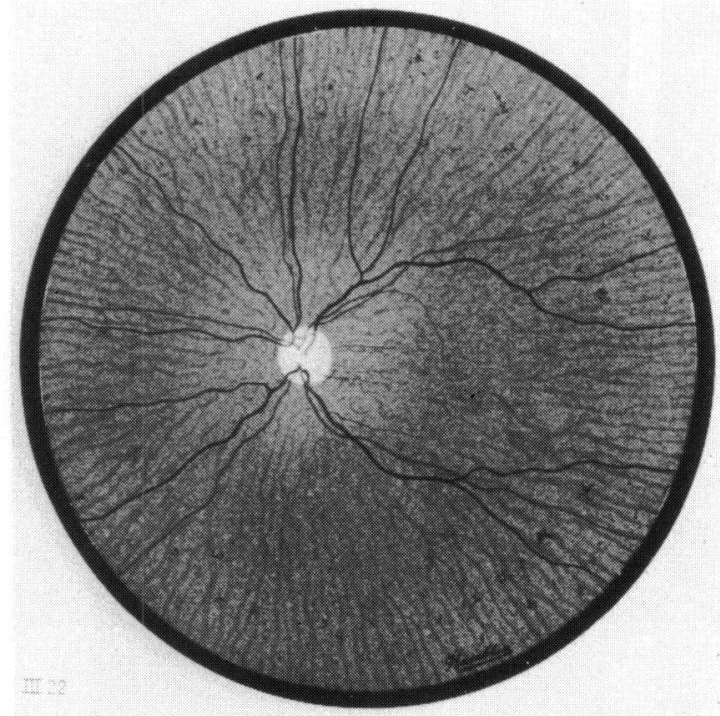

Fig. 2b

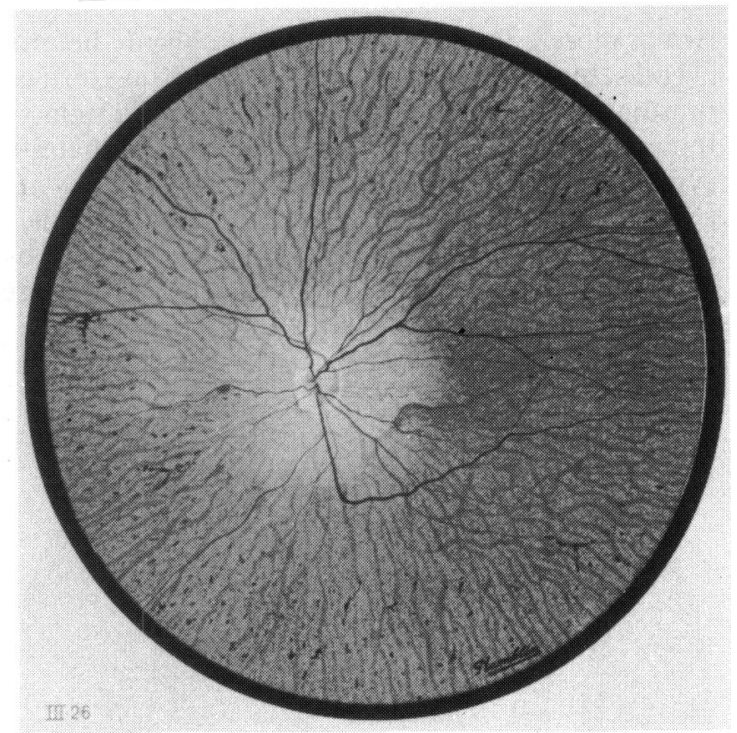

Fig. 2d

Fig. 2 Fundus paintings of affected males: (a) III/30 aged 3 years, (b) III/22 aged 8 years, (c) III/21 aged 10 years, (d) III/26 aged 11 years, (e) III/1 aged 30 years.

abnormal gene, whose normal chromosome complement includes one $\mathrm{X}$ and one $\mathrm{Y}$ chromosome, always express the disease. Affected males usually have night blindness in early childhood. When the disease has been present for some years, there is a characteristic fundus picture showing bone corpuscle pigmentation, attenuated retinal vessels, and pallor of the optic disc (Fig. 2); the diagnosis may be confirmed by electrodiagnostic tests. In some families it would be wrong to exclude the diagnosis before the early teens.

In $\mathrm{X}$-linked disease there is no father to son transmission, since sons receive their $\mathrm{X}$ chromosome from their mother, but every daughter of an affected male receives an $\mathrm{X}$ chromosome from her father and is a carrier, termed an obligate heterozygote. In the absence of a corroborative family history mothers of 


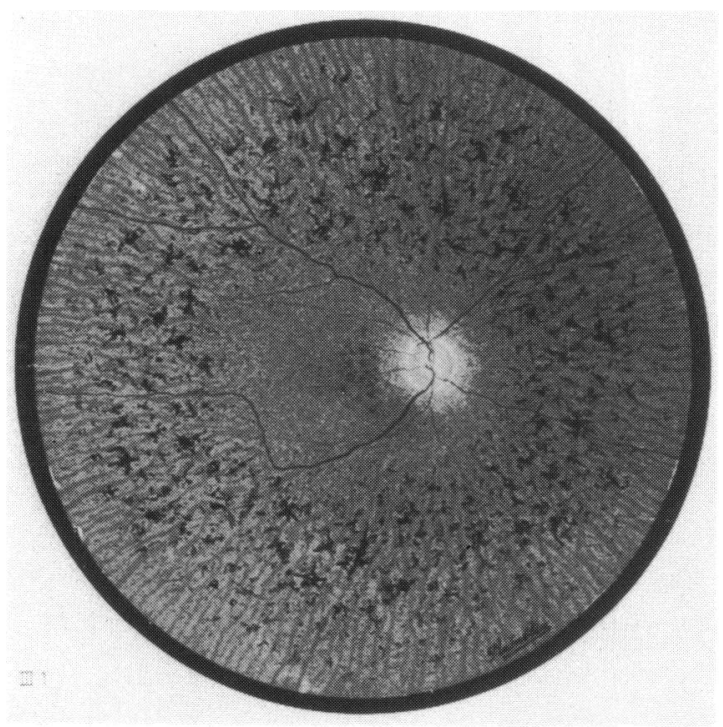

Fig. 2e

two or more affected males are also obligate heterozygotes, but mothers of one affected male are termed presumptive heterozygotes unless there are signs of the carrier state. The daughters of obligate heterozygotes are termed possible heterozygotes if they are clinically normal and obligate heterozygotes if they are clinically abnormal. XLRP is transmitted by heterozygotes, who have a $50 \%$ risk of having

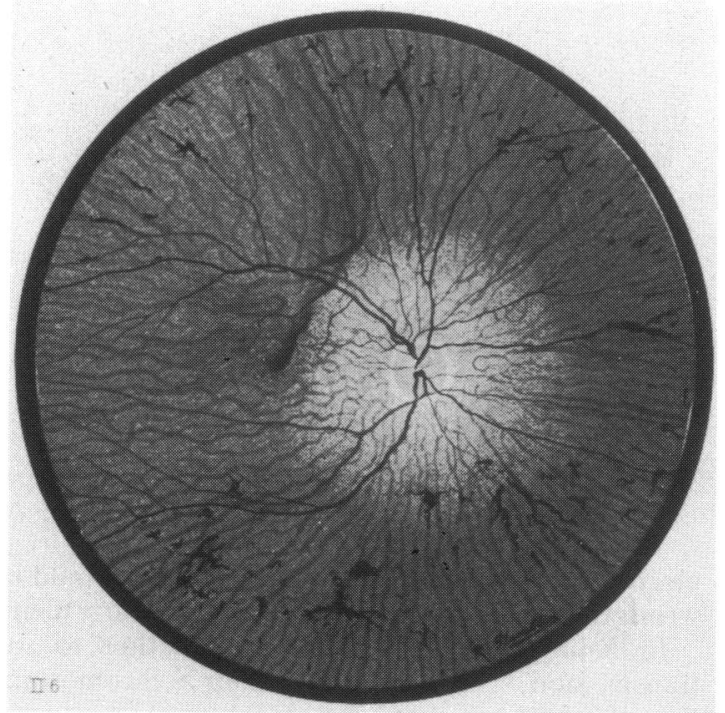

Fig. 3a (right) affected sons and the same risk of having daughters who will be carriers.

There is a wide spectrum in the expression of clinical signs in heterozygotes, which has been ascribed to the effect of random inactivation of the $\mathrm{X}$ chromosome. ${ }^{5}$ According to the Lyon hypothesis one of the two $\mathrm{X}$ chromosomes of the normal female is inactivated early in embryogenesis. This inactivation occurs at random, and the inactivated $\mathrm{X}$ chromosome, which forms the Barr body, may be maternal or paternal in origin. Once inactivation has taken place, the daughter cells will retain the same active $X$ chromosome. In particular, in a carrier female the cells which are destined to form the retina will comprise a proportion with a maternally derived active $\mathrm{X}$ chromosome carrying the gene for XLRP if she is the daughter of a heterozygote, and a proportion with a paternally derived active $X$ chromosome carrying the gene for XLRP if she is the daughter of an affected male. These proportions will vary from one carrier to another, as a result of random inactivation of the $\mathrm{X}$ chromosome. This will result in symptoms having a variable age of onset or being absent altogether, and a clinical picture which can vary from one that is occasionally almost as severe as in the affected male, to cases where the retina, by chance, consists largely of cells in which only the normal $\mathrm{X}$ chromosome is active and no visual deficits are manifest.

The detection of the heterozygous state of XLRP is often very difficult, but several methods have proved

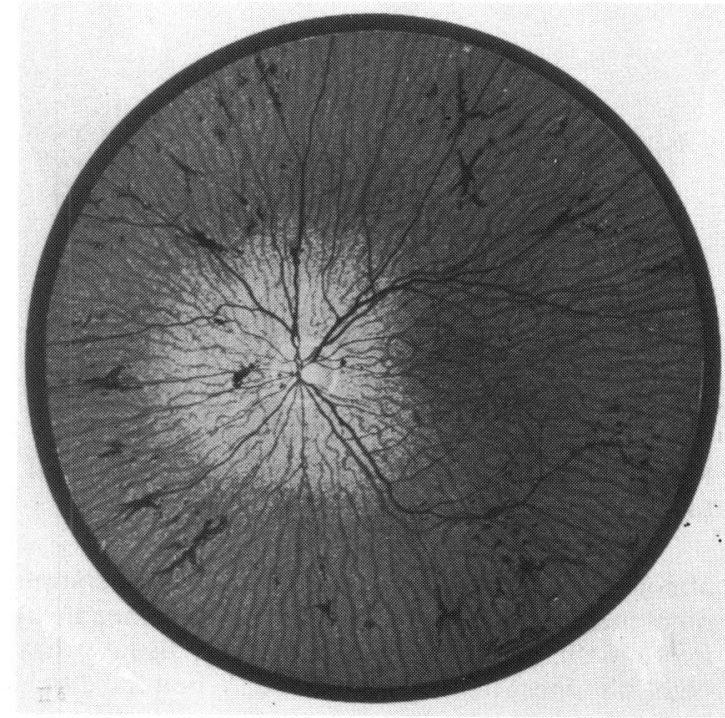

Fig. 3a (left)

Fig. 3 Fundus paintings of obligate heterozygotes: (a) II/6 aged 43 years, right and left eyes, (b) II/3 aged 54 years, right and left eyes, (c) II/1 aged 57 years, right and left eyes. 
helpful. Fundus changes can be identified in some carriers. A tapetal reflex or widespread retinal pigment epithelial changes with pigment migration are easily detected, but in most carriers the changes consist of small patches of pre-equatorial pigment epithelial thinning with or without pigment migration, or a grey appearance of the retinal pigment epithelium may also occur (Fig. 3). These latter changes may be slight, and especially in a blue-eyed individual the differentiation between a normal and an abnormal appearance of the retinal pigment

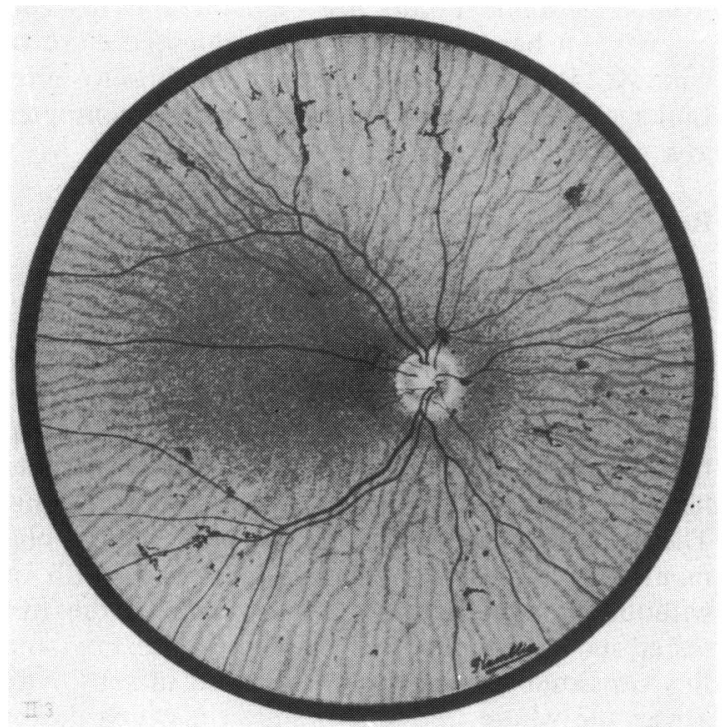

Fig. 3b (right)

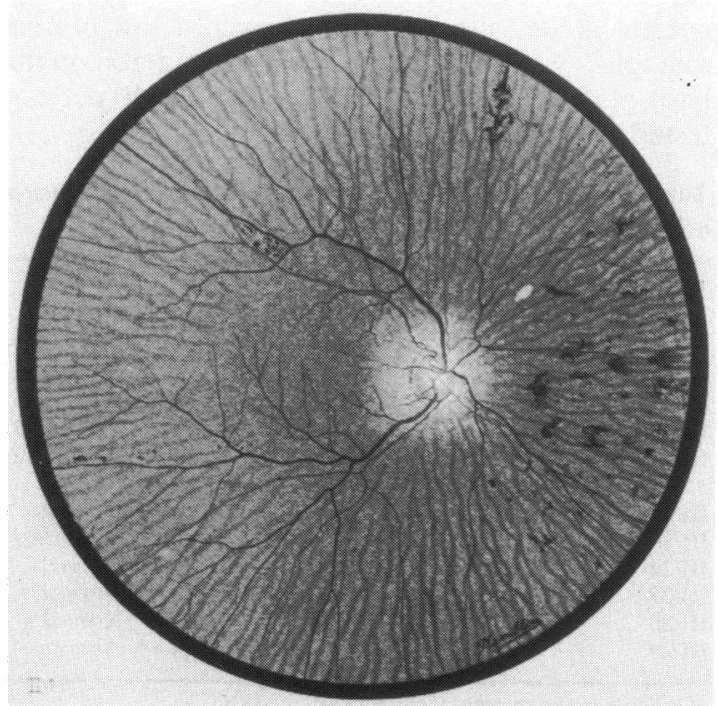

Fig. 3c (right) epithelium may be difficult. Abnormalities in the electroretinogram (increase of the time to peak of the response to white light flickering at $30 \mathrm{~Hz}$ and/or a decrease in the amplitude of the scotopic $b$ wave) have been demonstrated, ${ }^{6}$ but the detection rate of carriers by this method is only $50 \% .^{7}$ Variations from normal in flicker sensitivity have also been found both scotopically ${ }^{8}$ and photopically, ${ }^{9}$ but with this test only $60 \%$ of carriers are detected.

It is apparent therefore that more reliable and objective means of detecting the carrier state in an

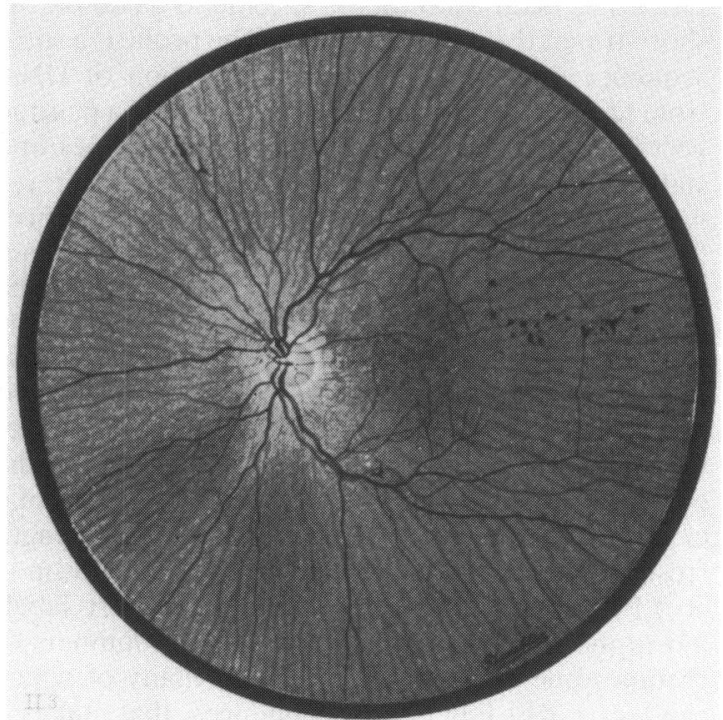

Fig. 3b (left)

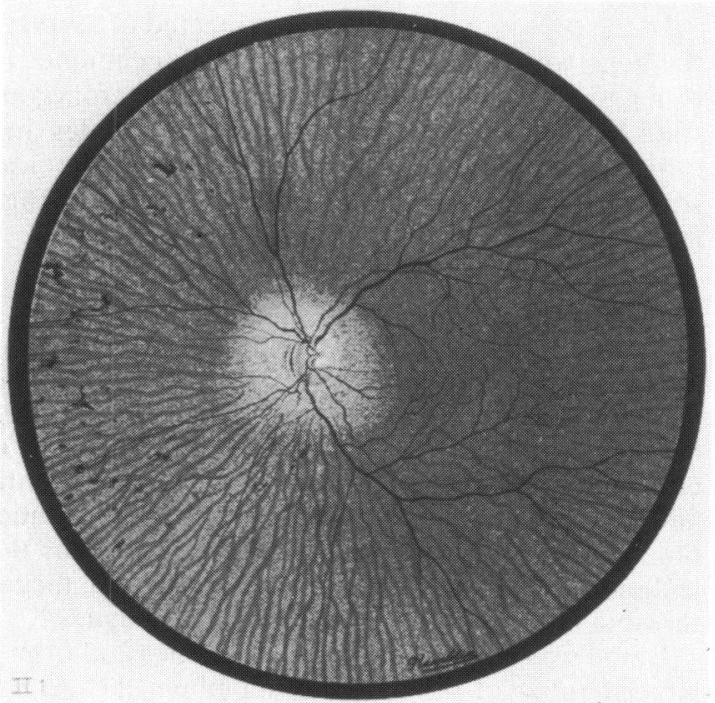

Fig. 3c (left) 
individual female would be helpful to the clinician. Linkage studies seek to detect the presence of the disease by identifying a marker situated so close to the disease gene that the risk of crossover is minimal. ${ }^{10}$ This method has the advantage that it can be performed at any age, since the genotype is established at conception and remains fixed throughout life. In the case of linkage markers identified by means of recombinant DNA probes there is the additional advantage of being independent of $X$ chromosomal inactivation.

An $X$ chromosome-specific recombinant DNA probe has been used that is specific to a site on the short arm of the $\mathrm{X}$ chromosome. The probe is a small sequence of DNA obtained by digestion of DNA from normal $\mathrm{X}$ chromosomes and cloned in a plasmid vector in order to provide sufficient quantities in a stable form for routine use. The linkage 'marker' is a variant nucleotide base (or bases), in the sequences flanking the probe, that occurs in a significant proportion of the population. The variant site can be detected only if it leads to a loss of one of the recognition sequences of a restriction endonuclease that normally cuts double-stranded DNA wherever it recognises a particular combination of 4-6 nucleotide bases. After electrophoretic separation of the endonuclease-digested DNA fragments the loss of a cleavage site is detected as an altered fragment length (restriction fragment length polymorphismRFLP) by hybridisation to the radioactively labelled probe. It is the availability of large numbers of chromosome specific DNA probes, many of which can locate RFLP in nearby sequences, that makes it possible to map genes and develop RFLPs close enough to be used for presymptomatic diagnosis."

In the present study females suspected of carrying the gene were investigated by several techniques in order to assess the probability of the heterozygous state being present. Blood from these females and other close relatives informative for linkage was subjected to analysis in an effort to find a linkage marker for the disease.

\section{Material and methods}

Ten females from the family were examined and tested, all of whom were the daughters of obligate heterozygotes. A history was taken and an ocular examination performed. Heterozygotes were identified by genetic criteria and recording ocular functions, including an electroretinogram (ERG), by the technique described by Arden et al., ${ }^{7}$ and flicker thresholds as described by Tyler and colleagues..$^{1213}$

Blood was taken from these $\mathbf{1 0}$ females and from a large number of other family members. DNA was extracted by the method of Kunkel and colleagues. ${ }^{14}$
It was digested to completion with the restriction endonuclease TaqI and photographed after electrophoresis in $0.8 \%$ agarose gels and staining with ethidium bromide. Gel DNA was denatured in alkali, neutralised, and transferred to nitrocellulose filters by the method of Southern. ${ }^{15}$ Filters were dried, baked, and hybridised overnight at $65^{\circ} \mathrm{C}$ in the presence of DNA from probe L1.28 labelled with ${ }^{32} \mathrm{P}$ dTTP by nick translation. Filters were placed next to an intensifier screen and exposed to $x$-ray film for 3-7 days. L1.28 is a random X-chromosome specific sequence cloned in plasmid pBR322 and isolated from a genomic library by Pearson and his colleagues ${ }^{16}$; it has been shown to be located close to band Xp11.3 on the short arm of the X chromosome. Linkage was analysed by means of the computer program LIPED. ${ }^{17}$

\section{Results}

CLINICAL AND ELECTRODIAGNOSTIC STUDIES The fundus appearance and electroretinographic and flicker results are summarised in Table 1 . All cases were asymptomatic and had a normal visual acuity. Six of the 10 were thought to have an abnormal fundus appearance, and two of these were obligate heterozygotes by definition, having affected sons. The fundus changes consisted of patchy retinal pigment epithelial atrophy in the periphery with or without pigment migration. Only two of the five tested showed an abnormality on flicker testing, and this consisted of a uniform reduction in sensitivity across the whole frequency range (in which flicker can be detected) in the peripheral field. An ERG was recorded from three subjects and all were within normal limits, although one showed a low normal scotopic b wave amplitude. It was considered on the basis of these results alone that six of the 10 persons tested were presumptive heterozygotes.

Table 1 ERG, flicker sensitivity, and fundus appearance in members of family

\begin{tabular}{llll}
\hline $\begin{array}{l}\text { Pedigree } \\
\text { Number }\end{array}$ & ERG & Flicker & Fundi \\
\hline III/3* & - & Normal & Abnormal \\
III/4 & - & Abnormal in periphery Abnormal \\
III/11* & Normal & - & Abnormal \\
III/13 & Normal & - & Abnormal \\
& (but low b wave) & & Normal \\
III/15 & - & - & Abnormal \\
III/18 & - & - & Normal \\
III/24 & - & Normal & Normal \\
III/27 & Normal & - & Normal \\
III/28 & - & Normal & Abnormal in periphery \\
III/29 & - & & Abnormal \\
\end{tabular}

*Obligate heterozygote, having an affected son. - Not done. 


\section{LINKAGE STUDIES}

The results of the linkage studies with $\mathrm{L} 1.28$ are shown in Table 2 and Fig. 4. The two marker alleles are labelled $\mathrm{A} 1$ and $\mathrm{A} 2$, corresponding to DNA restriction fragments of length 12 kilobases $(\mathrm{kb})$ and $9 \mathrm{~kb}$ respectively. It can be seen that all seven obligate heterozygotes in generation II carried allele A2 and at least six were heterozygous (A1-2) so that their offspring were informative for linkage. This means that the cosegregation or otherwise of alleles A1 and A2 with XLRP can be observed in their offspring. Allele A2 was found to be associated with XLRP in all 10 affected males and obligate heterozygous females in generation III, while allele A1 was associated with the seven tested unaffected males in generations II and III. It was assumed for the purpose of this study that 'at risk' females in generation III showing the characteristic fundus changes of carrier status and supported by other investigative techniques were presumptive carriers. Two 'at risk' females, shown to be carriers by these criteria, also received allele $\mathrm{A} 2$ from their mother, consistent with linkage between this allele and XLRP. However, two females (III/13 and III/29) showed fundus changes consistent with the carrier state and yet had marker status A1-1. Recombination may therefore have occurred between the XLRP and L1.28 loci in these cases. Four 'at risk' females in generation III were found to have normal results by fundus examination and other tests (Table 1), two of whom had alleles A1-1 and two of whom had A1-2 (allele A2 from mother). Since $\mathrm{X}$-inactivation may lead to false negative results in 'at risk' females, the genetic status of females not manifesting the changes of carrier status was not inferred for the purposes of the linkage study.

The linkage results have been analysed both including and excluding the results from carrier females diagnosed clinically (Table 2). In both cases it is likely that probe L1.28 is closely linked to XLRP

Table 2 Linkage data for XLRP

\begin{tabular}{|c|c|c|c|c|}
\hline & \multicolumn{2}{|l|}{$R P 22$} & \multicolumn{2}{|l|}{$A l l X L R P$} \\
\hline & Males only & $A l l$ & Males only & $A l l$ \\
\hline LOD $_{\max }$ & $5 \cdot 10$ & $3 \cdot 78$ & $6 \cdot 32$ & $6 \cdot 81$ \\
\hline $\boldsymbol{\theta}_{\max }$ & 0.00 & 0.09 & 0.00 & 0.05 \\
\hline $\boldsymbol{\theta}_{\text {mean }}$ & 0.05 & 0.13 & 0.04 & 0.08 \\
\hline $95 \%$ limits & $0 \cdot 0-0 \cdot 19$ & $0.02-0.30$ & $0.0-0.15$ & $0.01-0.19$ \\
\hline
\end{tabular}

Summary of the results of linkage analysis between L1.28 and XLRP in RP22 alone and combined with other XLRP families tested. The maximum likelihood $\left(\theta_{\max }\right)$ and mean $\left(\theta_{\text {mean }}\right)$ values of the recombination fraction are shown together with the LOD scores corresponding to $\theta_{\max }$ and the $95 \%$ confidence limits on $\theta$. The analysis of the data used clinical information from males only and from males plus females identified as carriers on testing.
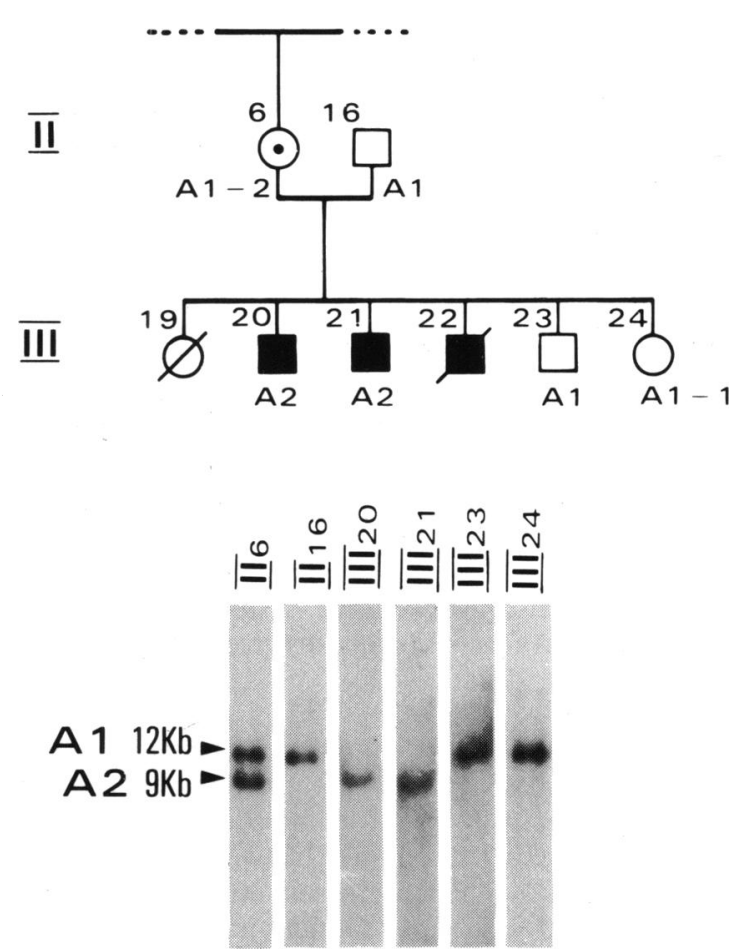

Fig. 4 TaqI endonuclease digested DNA from members of an RP22 family, probed with recombinant DNA clone L1.28. The mother (II/6) is heterozygous for the L1.28 polymorphism, since she shows two restriction fragments with bands at 12 kilobases ( $k b ; A 1)$ and $9 \mathrm{~kb}(A 2)$. The two affected sons (III/20, III/21) have the A2 allele, and the unaffected son (III/23) has the Al allele. The daughter (III/24) showed no abnormality on clinical testing and is homozygous for allele $A 1$.

with maximum LOD scores greater than 3 at a distance less than 10 centimotgans (cM). This compares with the genetic length of the $\mathrm{X}$ chromosome of about $250 \mathrm{cM} .{ }^{18}$ The current status of the linkage results in RP22 combined with other XLRP families is also shown in Table 2. The maximum likelihood value of the recombination fraction is 0.05 , and the upper $95 \%$ confidence limit is $0 \cdot 19$, indicating that the error due to recombination is very unlikely to exceed $20 \%$.

\section{Discussion \\ CLINICAL RESULTS}

The females who were examined as part of this study were seen over a period of several years, and hence the investigative techniques used to try and ascertain their genetic status have varied. The results obtained, however, serve to emphasise the low detection rate of the methods available at present. In our hands fundus 
examination still remains the most reliable means of diagnosis of the carrier state, especially within the context of a family history of $\mathrm{X}$-linked retinitis pigmentosa. The detection of $\mathrm{X}$-linked disease in an isolated individual and in the absence of a corroborative family history is at present extremely difficult and in some cases may be impossible.

\section{LINKAGE RESULTS}

Analysis of the linkage results in this family (identified at Moorfields Eye Hospital as RP22) suggests that there is close linkage between recombinant DNA probe L1.28 and XLRP. Similar results have been found in four other XLRP families, ${ }^{190}$ which is consistent with the gene in affected members of family RP22 being either identical with or closely linked to that causing XLRP in other families. The combined data from all families give $95 \%$ confidence limits for the distance between L1.28 and XLRP of 1-20 cM $(\theta=0 \cdot 01-0 \cdot 19)$ and a minimum error (mean) value of the recombination fraction of 0.08 , representing about $92 \%$ accuracy. The assignment of the L1.28 locus to the proximal short arm of the $X$ chromosome (in the region of band Xp11.3), suggests that the XLRP gene is in the same region. At present only some $40 \%$ of XLRP families are informative for the L1.28 polymorphism, and work is under way to try to extend this to a greater proportion of families. A predictive test with accuracy greater than $92 \%$ is most likely to be achieved by a combination of probes flanking the XLRP locus, though the ordering of closely linked loci is problematical. In addition to refining genetic distances one further source of uncertainty must be dealt with before the L1.28 polymorphism can be used clinically in all families, namely, the possibility of genetic heterogeneity. This problem does not arise with family RP22, within which linkage has been established, but it may do with other XLRP kindreds in which the possibility of XLRP loci not linked to L1.28 cannot be discounted until several-more independent families have been analysed.

COMBINED USE OF CLINICAL AND LINKAGE DATA IN XLRP CARRIER DETECTION

The use of information based on linked genetic markers as an aid in the detection of heterozygotes in XLRP is of potential importance, especially since DNA polymorphisms are unaffected by $\mathrm{X}$ chromosome inactivation and are independent of age. As information from genetic linkage and from clinical tests is essentially independent, it should be possible to combine the two sets of information quantitatively to allow a more accurate prediction than is possible from either set of data alone. This is already possible for such disorders as the $\mathrm{X}$-linked muscular dystro- phies, but unfortunately no accurate estimates exist for the likelihood of an XLRP heterozygote being classified as normal on the basis of clinical tests.

Until such information exists it is probably preferable to regard genetic linkage as strongly supportive of clinical tests when both predict the heterozygous state, while a prediction of normality would give a comparably strong reassurance, with an error unlikely to exceed $10 \%$. In individuals at high genetic risk who show unequivocal clinical features of the heterozygous state, but are predicted by linkage to be normal (for example, III/13 and III/29 in the present kindred), it is advisable to rely on the clinical evidence. Comparable caution is wise in advising those clinically normal female relatives whose genetic linkage evidence predicts that they have received the XLRP gene.

Where an obligate or presumptive heterozygote is pregnant and the fetus is known to be male, genetic linkage data may allow prediction as to whether the fetus has or has not inherited XLRP. Since both fetal sex and fetal DNA polymorphisms (including L1.28) can be reliably detected by chorion biopsy in the first trimester of pregnancy, it is important that those women in whom the prediction could be applied and who would wish for such testing are fully informed and investigated prior to embarking on a pregnancy.

Finally, it should be stressed that application of genetic linkage in prediction requires study of the family unit, not just an individual, an added factor in favour of studies being done before they are actually needed in making decisions regarding childbearing. Since full accuracy of prediction may require the availability of affected individuals or spouses in older generations, serious consideration should be given to obtaining samples from such individuals during their lifetimes, so that the opportunity for prediction in the younger generations is not lost.

We thank Mr Barrie Jay and Professor A C Bird, who examined the fundi of members of this family, and Professor G B Arden and Dr W J K Ernst, who allowed electroretinography and flicker sensitivity measurements to be performed in the Electrodiagnostic Department at Moorfields Eye Hospital.

Dr S S Bhattacharya was generously supported by the Sir Jules Thorn Charitable Trust, and the Gwent Association for the Blind funded travelling and transport costs. This study was also supported by: MRC Grant G80/0986/7/N; a grant from the British Retinitis Pigmentosa Society, and a grant from the National Retinitis Pigmentosa Foundation, Inc.

\section{References}

1 Hoare GW. Chorioretinal dystrophy. Br J Ophthalmol 1965; 49: 449-59.

2 Bird AC. X-linked retinitis pigmentosa. Br J Ophthalmol 1975; 59: 177-99.

3 Kobayashi F. Genetic study on retinitis pigmentosa. Jpn J Ophthalmol 1960; 4: 82-8. 
4 McKenzie DS. The inheritance of retinitis pigmentosa in one family. Trans Ophthalmol Soc NZ 1951; 5: 79-82.

5 Lyon MF. Gene action in the X-chromosome of the mouse. Nature 1961; 190: 372-3.

6 Berson EL, Gouras P, Gunkel RD, Myrianthopoulos NC. Rod and cone responses in $\mathrm{X}$-linked retinitis pigmentosa. Arch Ophthalmol 1979; 81: 215-25.

7 Arden GB, Carter RM, Hogg CR, et al. A modified ERG technique and the results obtained in $\mathrm{X}$-linked retinitis pigmentosa. Br J Ophthalmol 1983; 67: 419-30.

8 Ernst WJK, Clover GM, Faulkner DJ. X-linked retinitis pigmentosa: reduced rod ficker sensitivity in heterozygous females. Invest Ophthalmol Visual Sci 1981; 20: 812-6.

9 Ernst WJK, Tyler CW. Differential temporal visuogram losses associated with genetic classes of retinitis pigmentosa. ARVO Suppl 1982; 22: 137.

10 Wright AF, Bhattacharya SS, Price WH, et al. DNA probes in X-linked retinitis pigmentosa. Trans Ophthalmol Soc UK 1983; 103: 467-74.

11 Weatherall DJ. The new genetics and clinical practice. Oxford: Nuffield Provincial Hospitals Trust, 1982.

12 Tyler CW, Ernst WJK, Lyness AL. Photopic flicker sensitivity losses in simplex and multiplex retinitis pigmentosa. Invest Ophthalmol Visual Sci in press.
13 Tyler CW. Specific deficits of flicker sensitivity in glaucoma and ocular hypertension. Invest Ophthalmol Visual Sci 1981; 20: 204-12.

14 Kunkel LM, Tantravahi U, Eisenhard M, Latt SA. Regional localization on the human $X$ of DNA segments cloned from flow sorted chromosomes. Nucleic Acids Res 1982; 10: 1557-78.

15 Southern EM. Detection of specific sequences among DNA fragments separated by gel electrophoresis. J Mol Biol 1975; 98: 503-17.

16 Pearson PL, Wieacker P, Bakker B, Prins HA. A restriction site polymorphic marker for the short arm of the $\mathrm{X}$ chromosome. Clin Genet in press.

17 Ott J. Estimation of the recombinant fraction in human pedigrees: efficient computation of the likelihood for human linkage studies. Am J Hum Genet 1974; 26: 588-97.

18 Ropers H-H, Wieacker P, Wienker TF, Davies K, Williamson R. On the genetic length of the human $X$ chromosome. Hum Genet 1983; 65: 53-5.

19 Wright AF, Bhattacharya SS, Price WH, et al. A genetic linkage study of X-linked retinitis pigmentosa. J Med Genet 1984; 21: 140.

20 Bhattacharya SS, Wright AF, Clayton JF, et al. Close genetic linkage between $\mathrm{X}$-linked retinitis pigmentosa and a restriction fragment length polymorphism identified by recombinant DNA probe L1.28. Nature 1984; 309: 253-5. 